\title{
Asset Management Planning - providing the evidence to support robust and risk-based investment decisions
}

\author{
Chrissy Mitchell ${ }^{1, a}$, Kevin Woodley ${ }^{1}$, Owen Tarrant ${ }^{1}$, Jon Wicks ${ }^{2}$, Petra Neve ${ }^{2}$, Jonathan Simm ${ }^{3}$ and Jaap Flikweert ${ }^{4}$ \\ ${ }_{1}^{1}$ Environment Agency, Kingsmeadow House, Kingsmeadow Road, Reading, RG1 8DQ, UK \\ ${ }^{2} \mathrm{CH} 2 \mathrm{M}$, Burderop Park, Swindon, SN4 OQD, UK \\ ${ }^{3}$ HR Wallingford, Howbery Park, Wallingford, Oxfordshire OX10 8BA, UK \\ ${ }^{4}$ Royal Haskoning DHV, Rightwell House, Bretton, Peterborough, PE3 8DW, UK
}

\begin{abstract}
Over the last decade the UK's joint Flood and Coastal Erosion Risk Management Research and Development programme has been developing methods to support a move to a risk-based approach to flood defence asset management. Looking to ensure investment is less 'find and fix' and made to those assets where the biggest risk reduction can be made for the money available. In addition, providing the capability to articulate the benefits of investing in these assets quantitatively and transparently. This paper describes how the Asset Performance Tools (APT) project [1] is delivering practical methods, prototype tools and supporting guidance which, together with related initiatives such as the Environment Agency's Creating Asset Management Capacity (CAMC) strategic programme [2] and the 'State of the Nation' ( $\mathrm{SoN}$ ) [3] supportive datasets, will enable a risk-based, 'predict and protect' approach to asset management. A key advance is the ability to bring in local knowledge to make national generic datasets locally relevant. The paper also highlights existing outputs that can already be used to support a more proactive approach to asset management. It will summarise the ongoing work which will further develop and fine tune performance assessment and investment decision processes within an integrated conceptual framework aligned with ISO55000, deliverable via CAMC and whose concepts can be used by all risk management authorities.
\end{abstract}

\section{Asset Management Development}

Recent flood events have tested a large proportion of the UK's flood and coastal assets, increasing the pressure on investment to maintain assets at an appropriate standard. To enable the effective prioritisation of our current and future investment we must be able to assess the likely performance of individual assets in their current and improved states as well as understanding this performance within the context of the asset system.

Research is under way to develop an integrated framework to guide a flood and coastal erosion risk management (FCRM) authority in selecting the appropriate tools to determine:

1) How should the assets be performing?

2) How are the assets performing?

3) What is the most cost effective way of closing the gap between desired and actual performance?

The fully integrated framework allows users to understand the improved FCRM decision making process. It illustrates information flows, and how and when the tools and methods should be used to support decision making.

\section{Reviewing Asset Management Tools}

There already exist a number of tools available to support FCRM asset management decision making, for a range of assets and asset systems, each with their own advantages and disadvantages. This research reviews the functionality of existing tools and identifies what adaptive measures are required to maximise their capability and performance. This includes;

- how to integrate them into an asset management framework that better supports asset management decision making, and

- where and how it will be most beneficial to improve FCRM asset management tools and processes.

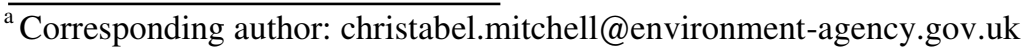




\section{Asset Management Planning}

To ensure the most cost effective asset investment regime is adopted, FCRM authorities need to be able to quantify and compare the benefits of both capital and maintenance activities, considering the likelihood and the probability and consequence of assets failing to perform as required. This research looks to improve existing benefit modelling tools, such as the modelling decision support framework (MDSF2) [4] to efficiently assess the benefits (risk reduction) of implementing different asset

\section{Asset Inspection}

New guidance is available on asset inspection [5]. The guidance incorporates the findings of current best practice, offering recommendations for improvement. The tiered framework on which the recommended asset management cycle is based integrates key activities in the management regimes. This information, together with the improved asset performance assessment methodology, is used to develop a whole life cost tool to compare the benefits of different investment scenarios. Expressing the flood risk reduction benefits of maintenance, using the same terminology as for capital investment, will create a stronger investment business case. This can help justify cost effective maintenance practices that could reduce total expenditure within an FCRM system, freeing funds to reduce flood risk elsewhere.

assessment cycle and directs the user to the appropriate level of activity according to assessed risk through a process of tiering (Fig.1.). Advancement up the three tiers is made in response to increasing levels of assessed risk.

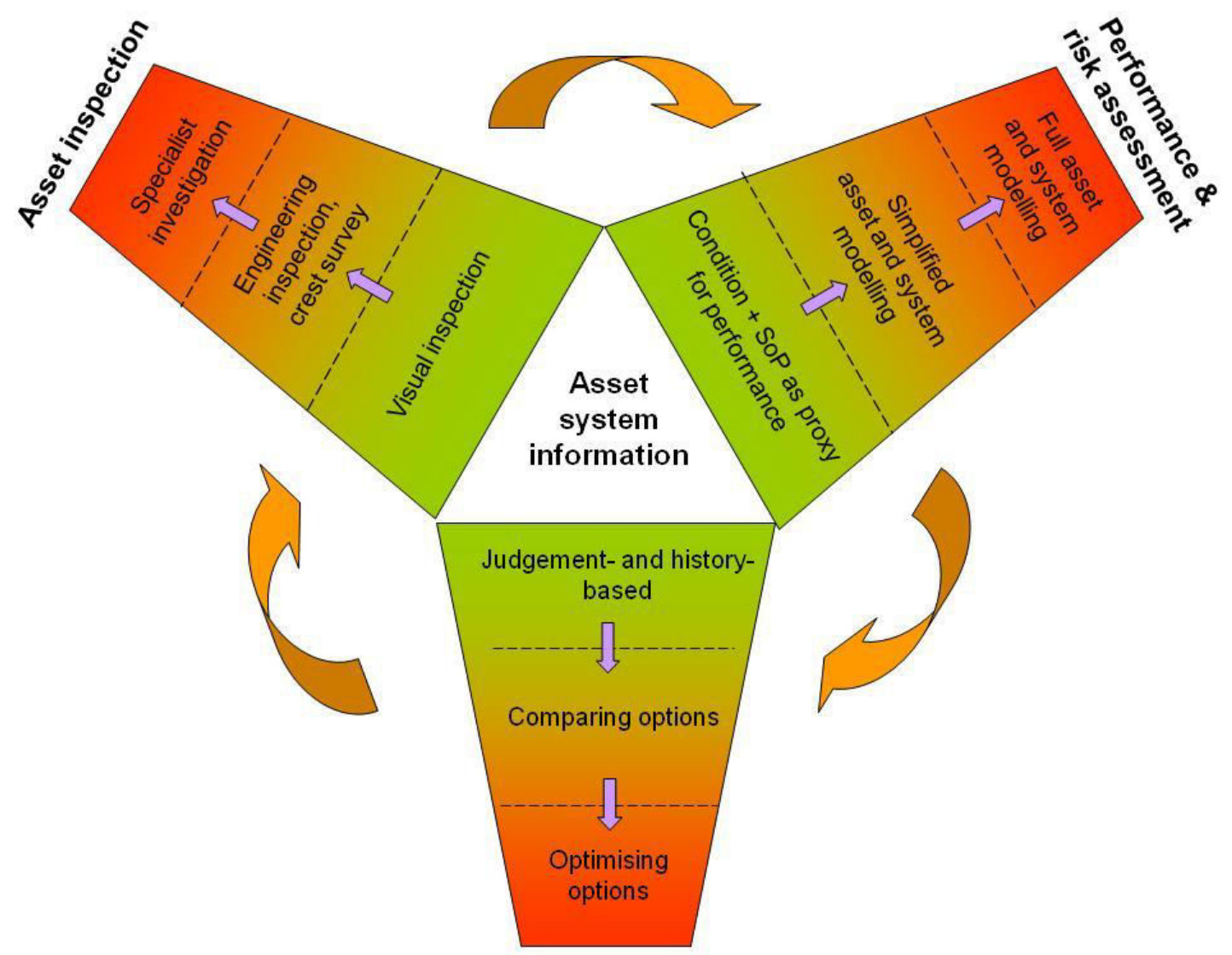

Asset management planning incl. investment decision making

Figure 1. The wings of the Propeller are the three 'tactical' elements of asset management: inspection, performance and risk assessment, and planning and investment decision making; information management lies at the heart. The Propeller shows how these activities relate. It also shows that inspection, performance assessment and planning typically involve a tiered approach: using basic methods for the majority of assets at low risk (where the wing is wide and green - tier 1), but more specialist methods for the small number of high risk assets where needed (where the wing is narrow and red - tier 3 ). 
Research shows that inspections can be targeted to need and interventions can be timed to pre-empt expensive and often distressing asset failure, rather than dictated by routine alone. Inspections are driven by a considered balance of investment and flood risk, offering the greatest impact on risk reduction at least cost.

Each flood risk management asset should have a target condition set for it taking into account risks and consequences. Application of the asset inspection process will ensure efficient management of assets through proactive planning and application of a risk-based approach rather than relying on a reaction to a failing asset, or one falling below its target condition.

- beach structures

- $\quad$ structures and point assets

Further information within the guidance includes:

- the relationship between condition and performance and why their monitoring is vital

- the risk-based approach to frequency of inspection

- $\quad$ how to inspect for engineering integrity

- $\quad$ different types of tier 2 and tier 3 inspections

- health, safety and environmental considerations

To establish relative priorities and confidence in the asset management process, consistent reporting and decision making is essential. It is also important to be able to demonstrate how decisions have been made for auditing reasons. Embedded in the guidance document is a prototype tool in the form of a Microsoft Excel spreadsheet. This tool is intended to serve as a baseline model for developing a consistent interface between 'inspection activities' and 'performance and risk activities'. The basis of the tool is a standardised series of picklists designed to bring consistency and direction to actions following tier 1 inspections.

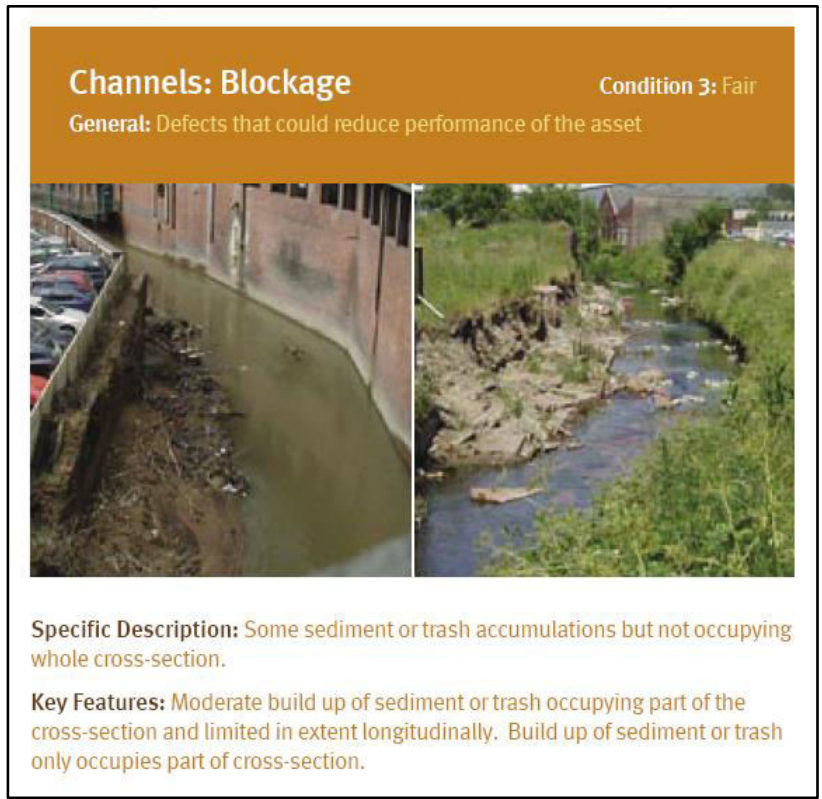

Figure 2. The Environment Agency condition assessment manual, used by asset inspectors to provide an asset condition graing from 1-5. Environment Agency, 2006.
The guidance recommends the triggers for moving from routine visual inspections (tier 1) to more advanced inspections at an intermediate (tier 2) or higher (tier 3) level. It also describes the need to integrate 'asset inspection'with assessments carried out under the two other propeller 'wings' within Figure 1 - 'performance and risk' and 'planning and investment decision making'.

The structure of the guidance document is in line with the grouping of asset types in the Environment Agency's Asset Information Management System (AIMS), that is:

- channel and culverts

- linear defences

- coastal defences

As a result of this research the following outputs are currently being put in place operationally:

- Recommendations' picklists are being built into the Asset Inspection Tablet 'App' currently being developed to improve mobile working for asset inspectors. This will enable a better data consistency, allow faults (either data or asset condition) to be reported and fixed more efficiently, and improve reporting capabilities.

- Reviewing the recommendation for a consistent Asset Defect Form. This is to be built into the CAMC system, so that defects can be raised and flagged up to the Asset Performance Teams immediately. This allows quick decision making on the next course of action -which can follow the principles of the APT report (i.e. triggering a tier 2 inspection, or immediate remedial work)

- In the longer term, to use the Engineering Integrity Matrices - turning them into additional pages of the Condition Assessment Manual (Fig.2.) to allow inspectors to spot likely failure modes for each asset type, and to determine what further action may be required. This not only increases the skills of the Inspector group, but also moves the business towards more 'performance based' inspections.

\section{Current developments}

The following sections of this paper refer to the products being developed under the current phase of research, completing Autumn 2016. The way that the research and associated products fit together is outlined in Figure 3. 


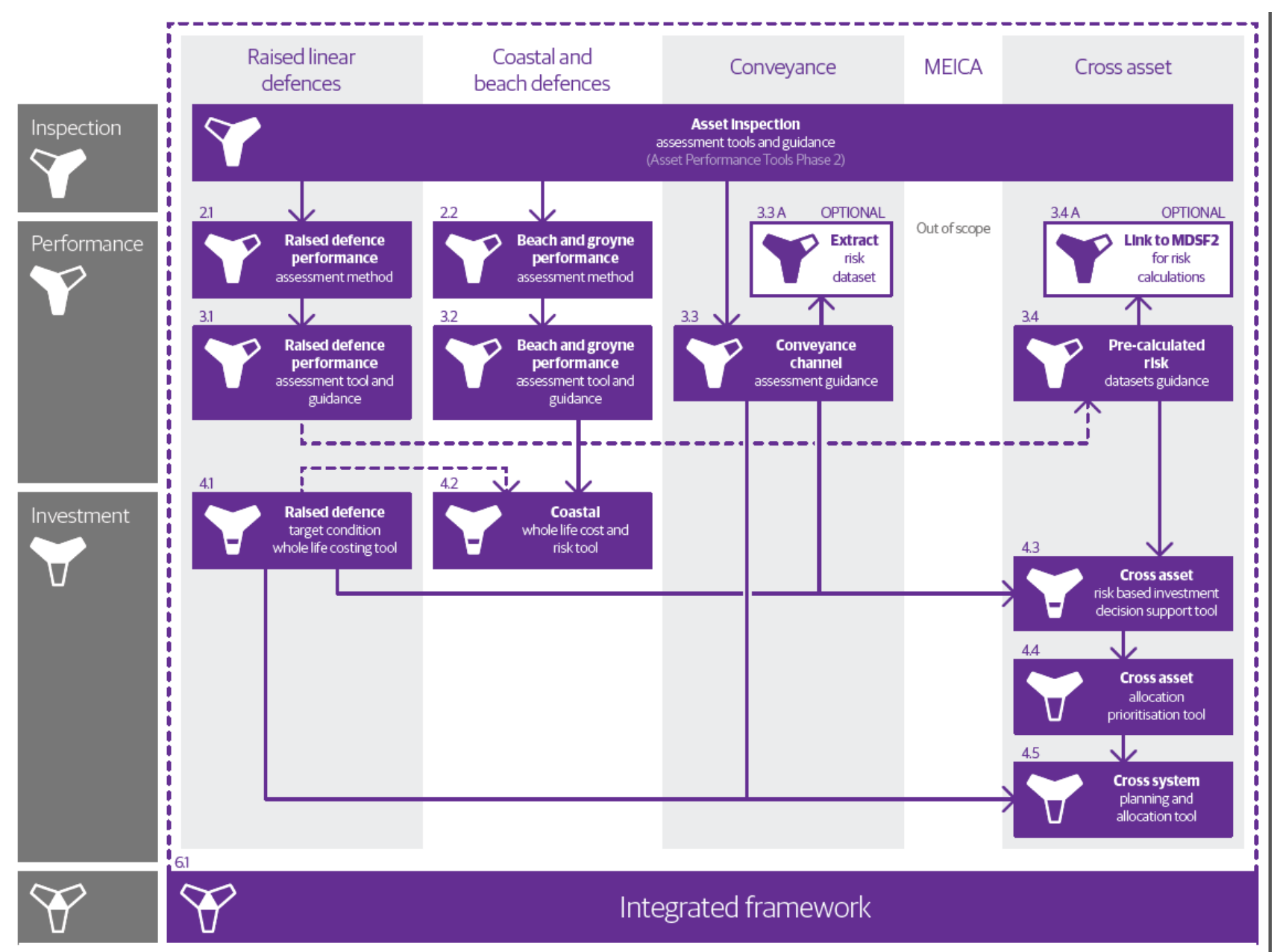

Figure 3 The framework of research, highlighting which tiers of the propeller diagram (Fig.1) are being developed (shaded parts of mini propellers within this figure). The product numbers 2.1-4.5 highlighted at the top of each box are referenced throughout this paper.

\subsection{Raised defence performance assessment method (Fig.3, Product 2.1)}

A method that translates practitioners' knowledge and understanding of the assets and their performance into asset specific fragility and deterioration curves. The method asks practitioners for their non-specialist and / or deterministic knowledge, in their own language, and translates this to the formats of the curves. These curves then feed into the investment planning and decision support tools and determine the asset specific versions pragmatically by reshaping and / or moving the existing generic curves. This enables the use of system risk models to support asset management of high risk critical systems. Directly because these models can then represent assets at the appropriate level of detail; indirectly because the asset managers of these systems are more likely to have confidence in these models because they have helped create them. In addition, this will improve the quality of the models that support national scale decision making (NaFRA [6], FaCET [7], SoN [3]) and also support a structured assessment of failure methods and potential mitigations (without recourse to system risk models). 


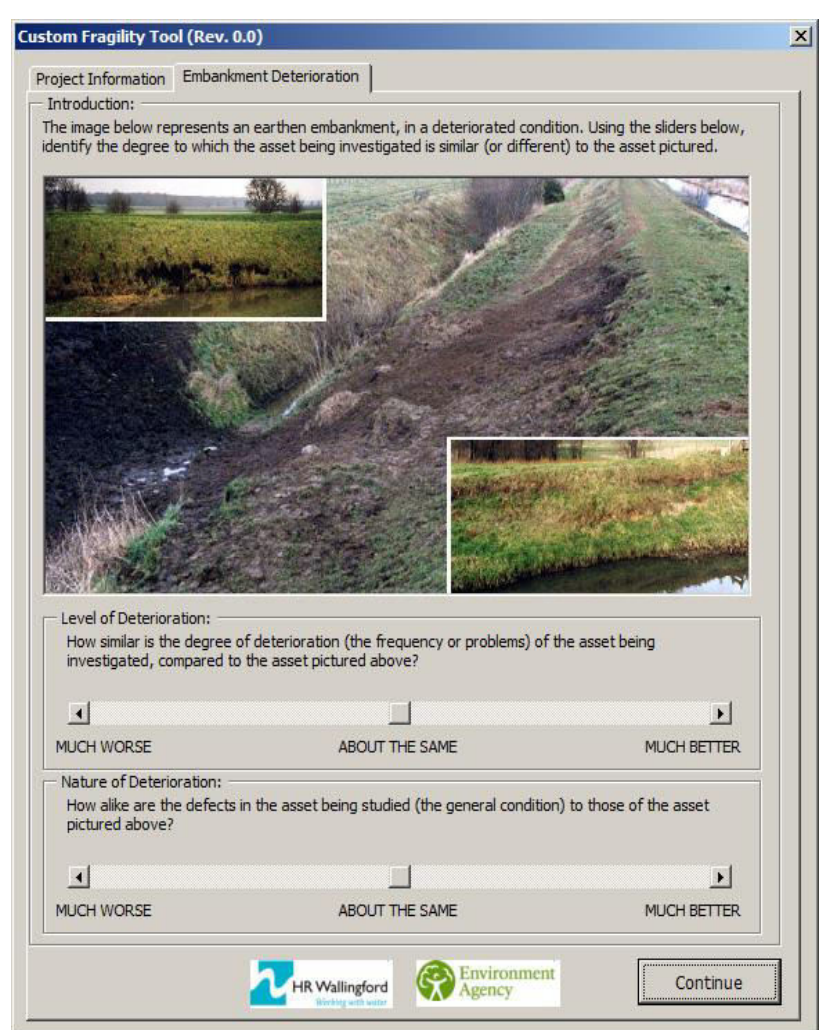

Figure 4 A prototype 'mock-up' of what the tool might look like, with user friendly slider bars capturing peoples knoiwledge of the asset.

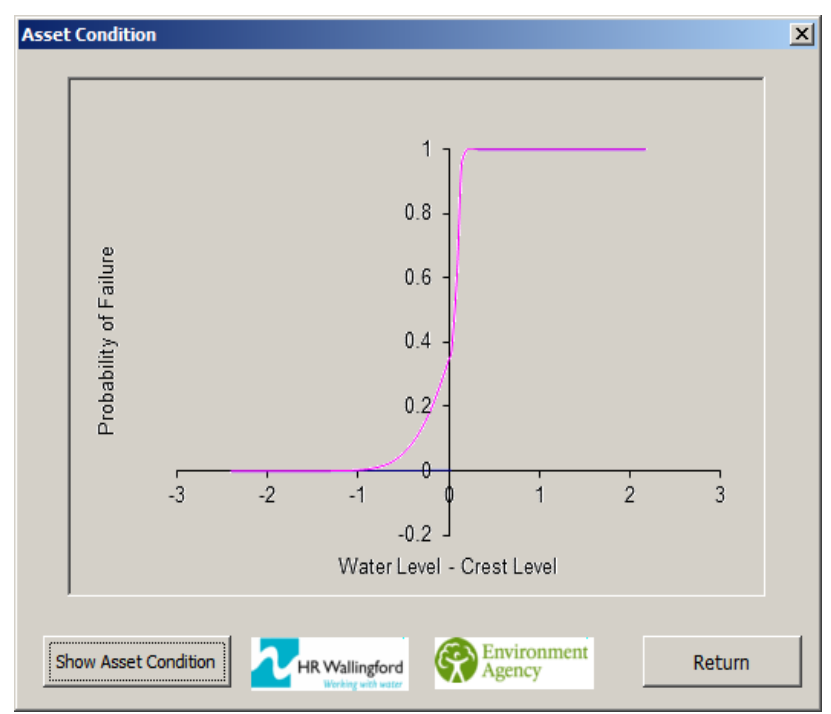

Figure 5 An example of the fragility and deteoriation curves that are the basis of the defence performance assessment.

\subsection{Beach and groyne performance assessment method (Fig.3, Product 2.2)}

A method, to help coastal engineering practitioners in the development of beach performance indicators and associated thresholds, including:

- how to select the indicators in specific situations.

- how to identify threshold values given the required performance of the beach and/or the fragility/performance of adjoining coastal structures.
- $\quad$ how to determine groynes profiles and acceptability of structural condition

This product provides guidance on indicators and thresholds (e.g. for crest levels and cross sectional areas/beach volumes), needed to deliver a measure of consistency in the evidence base used for decision making (with an appropriate audit trail). It allows groynes to be assessed in a way that reflects the degree of deterioration at various locations along the groynes. This supports the maintenance of groynes profiles that better reflect the need for adaptive management of beach profile. The work builds on that of existing guidance in the UK Beach Management Manual and draw on best practice and available research (such as the ConSCIENCE project [8], Channel Coastal Observatory work [9], CoaEST [10], iCOASST [11]).

\subsection{Raised defence performance assessment tool and guidance (Fig. 3, Product 3.1)}

An Excel-based tool that can develop fragility and deterioration curves based on readily available asset information and practitioner experience. It use local knowledge to develop asset-specific curves that can ultimately be used to improve the national understanding by improving existing risk models such as MDSF2 and RAFT [4], as well as NaFRA [6] and FaCET [7]. The tool uses the method developed in Product 2.1. The tool's user interface matches the practitioners' level of understanding and is supported by user-focused guidance. Involving practitioners directly in the improvement of these vital parts of the planning and risk tools has helped to reduce the perceived 'black box' nature and increase confidence in the tools.

\subsection{Beach and groyne performance assessment tool and guidance (Fig.3, Product 3.2)}

In terms of coastal flooding, the State of the Nation and NaFRA project has made important advances by:

(a) providing higher fidelity coastal hydraulic boundary conditions and

(b) producing better predictions of overtopping rates.

However the challenge that remained is the beach level values that input into the overtopping predictions which ultimately determine flood risk and risk attribution to the flood defences. State of the Nation information is used to pre-calculate structure overtopping rates for a range of beach profiles (as analysed from raw data using a tool such as SANDS or BDAS) and input these overtopping rates into a RAFT-type tool which shows the benefits associated with maintaining beaches at different levels (for various degrees of future sea level rise).

The method described above will not be applicable for coastal protection structures. Overtopping is less relevant as failure of protection structures is driven more by combinations of wave and water level conditions together with beach levels. However, the link between failure and multivariate loading conditions has not yet been fully established so a few exemplar situations are being examined to identify options.

A method is also provided that allows the crest profile and required condition/performance of groynes to be assessed in a way that reflects the likely degree of variation 
in beach level along the groynes and the anticipated rates of deterioration. This supports the maintenance of groyne profiles and improves the need for adaptive management of beach profiles. The asset manager can then determine what beach level and/or volume is required on the basis of the known degree of risk reduction (economic benefits) required to be delivered by the beach sea/wall combination. This can then be used to design the capital / maintenance investment scheme and to justify the relevant expenditure.

The products from this task support the method and guidance developed in Product 2.2.

\subsection{Channel conveyance assessment guidance (Fig.3, Product 3.3)}

There already exist quite a number of tools in this area, so guidance will be provided that gives a pragmatic approach for quantifying the flood mitigation benefits of conveyance work. It will also support the justification and communication of the consequences of maintenance works or their withdrawal.

Flood Risk Management conveyance assets include culverts and natural and engineered open channels. Performance is impacted mainly by:

- blockages (from natural material, urban debris or structural failure of the culvert/channel) which can occur at structures or at any point in the channel

- increased roughness caused by vegetation

- reduced cross sectional area through siltation

The guidance:

- describes overarching processes (workflows) for assessing the flood impacts / consequences of changes in the performance of the key conveyance assets (listed above).

- describes tier 1,2 and 3 methods using existing tools, guidance and data sets.

- includes examples to illustrate application of the methods.

- discusses limitations of methods and reasons to switch between tiers.

- tightly links into the APT3 Asset Management Framework, for example the object of the performance assessment is to generate evidence of management options and their expected benefit.

It will have a strong link to the Channel Management Handbook [12] (i.e. explain the processes and tools that can be used for the scenarios set out in the Handbook), Aquatic Plant Management Guidance and Debris Blockage Guidance.

\subsection{Pre-calculated risk datasets guidance (Fig.3, Product 3.4)}

Guidance on the use of pre-calculated risk data sets is required to enable a strong risk based approach to asset management planning that does not require new local runs of MDSF2. It is provided to extract/make use of precalculated assessments of risk available from State of the Nation, future NaFRA and other sources. This data will be available for both present asset condition and potentially future conditions.

The pre-calculated data sets will support locally made risk/benefit calculations for maintenance investment enable the development of additional planning tools:

- Firstly, a Whole Life Investment model (Product 4.3) can be developed that makes use of the risk data within the calculation, to allow more active trade-off between investment and risk.

- Secondly, a system or portfolio level model (Product 4.5) can be used to support and inform the allocation process within AIMS Planning and potentially assist local asset managers in selecting the appropriate target condition grade.

\subsection{Tool to support pre-calculated risk data guidance (Fig.3, Product 3.4A)}

None of the other tools listed herein allow the possibility of assessing the impact on residual risk of locally adjusted fragility curves (as delivered by products 2.1/3.1) or revised return period water levels delivered by conveyance interventions. To address this problem and deliver revised assessments of risk attribution in a user friendly manner, a tool is planned that interfaces directly with MDSF2. This user interface would take input in the form of revised fragility curves and/or water levels and execute MDSF2 to obtain the revised risk estimates. Benefit information will be made available on a system or asset basis of each user defined maintenance scenario. As the user interface tool is stand-alone, there would also be no requirement for expensive and time-consuming updates to the tool when new or improved information or analysis routines are provided to the MDSF2 system. The tool would make it easy for users to specify the inputs.

\subsection{Raised defence whole life cost planning tool and guidance (Fig.3, Product 4.1, Tier 2)}

The deliverable will be a whole life cost (WLC) Excel-based tool and user guide to support asset management practitioners in identifying the most cost effective investment regime for raised defences. The tool will use deterioration profiles to assess the impact of maintenance of defined maintenance activities on asset deterioration and support the user in identifying the least cost investment regime required to deliver the target condition grade. This product is a refinement of the existing prototype WLC tool that was developed as part of the FCRM assets: deterioration modelling and WLC analysis (report SC060078). New functionality will include:

- improvements to usability;

- ability to modify deterioration curves based on user judgement and/or outputs from the Product 3.1 tool

- $\quad$ ability to save analysis results and input data;

- development of interfaces and automated generation of outputs for 'risk based investment planning' using the Product 4.3 tool.

Periodic maintenance activities are often carried out based upon historical practice, local judgement, or a 
combination of the both. As a result, maintenance investment is not always undertaken in the systems or on activities where it can yield the greatest value. This tool will help_local asset managers estimate maintenance costs and options for maintaining assets at target condition grades. It also allows users to tweak parameters and answer such questions as - what if I place more pressure on the asset? What if I do nothing?

\subsection{Coastal whole life cost planning scoping report (Fig.3, Product 4.2, Tier 2)}

A scoped report is being developed, which if implemented will help coastal erosion asset managers justify investment in maintenance by connecting performance of their assets to risk; bringing together the outcomes of the tools from Product 2.2/3.2 with the concepts developed in the RACE study from 2007 [13]. Expressing benefits of maintenance using the same terminology as for capital investment will create a stronger business case within coastal risk management authorities. This can help justify cost effective maintenance practices that could reduce total expenditure with a coastal system, or identify where the risk is sufficient to warrant additional investment.

\subsection{Cross asset risk based investment decision support tool (Fig.3, Product 4.3, Tier 2/3)}

An Excel-based prototype investment planning tool that can account for risk within the life cycle cost calculation to better describe the relationship between investment and performance and risk. The tool will use the same deterioration curves and maintenance assumptions as the Product 4.1, but will estimate and account for the increased risk exposure as the asset deteriorates from one condition grade to the next. This asset level risk data will initially be available via NaFRA/SoN (using Product 3.4 guidance). The product will be a prototype designed to show what may be possible as the Environment Agency develops into an increasingly mature asset management organisation.

The tool will support risk-based (as opposed to purely condition-based) asset management and will:

- Allow user to compare options

- Identify the investment regime that yields the best value in terms of the balance of WLC and risk within an FCRM system unit.

- Support effective operational and maintenance decisions. For example, the tool can be used to quickly identify the high risk areas requiring investment. It can also be used for re-programming maintenance should funding levels change and identify the best use of available funds.

- Have the potential to target investment on those assets or asset types within the system where the risks or benefits are greatest.

\subsection{Allocation Prioritisation Tool (Fig.3, Product}

Development of a re-prioritisation tool to support local users in reprogramming their maintenance budget. The need for such a tool had been clearly identified at a practitioner's workshop to support maintenance reprogramming against the allocated budget. This product will develop / trial the existing "trade-off" tool in use in the transportation sector. The tool supports budget allocation (and re-allocation) based on evaluation against multiple performance measures, compares options / scenarios and provides 'trade-off' analysis between portfolios and between individual projects, allocating budgets to specified activities.

\subsection{System based planning \& allocation tool (Fig.3, Product 4.5, All Tiers)}

A guidance document is being developed supported by a simple tool that makes use of available asset and benefit/risk information and will take flood defence asset managers through the calculation of flood defence benefits at system level.

This product makes use of the pre-calculated MDSF2/NaFRA/SoN data sets and whole life investment data to support the identification of system benefits associated with differing investment regimes. It improves information over and above NaFRA, which provides a simple analysis that doesn't differentiate between maintenance. The resulting product provides guidance for end users, including advice on where to obtain the input data. Data input would include such information as the risk attribution to assets and the number of houses protected (put at risk by failing assets).

The tool could support the maintenance allocation process by identifying the benefits of differing maintenance regimes. It could also be used to support asset managers in identifying the most cost beneficial target condition grade for a flood risk system both at a local and national level. It may also help improve the short/medium term allocation of asset maintenance funds (next 5 years) i.e. assisting with the annual process of allocating revenue budget at system level.

\subsection{Integrated Framework (Fig.3, Product 6.1 \& 6.2)}

The Asset Management Risk Framework will support users in deciding which tier of methods is most appropriate to use for specific decisions. It will facilitate the move from condition based asset management, to performance and serviceability driven asset management, where the risks merit. The Asset Management Risk Framework will support risk based asset management decision making, facilitating future ISO 55000 accreditation. More practically it will increase transparency within asset management decision making and allows users to understand how and why the different tools work together. The framework can be used to plan next steps and enable continual improvement of the FCRM Asset Management System. Specific guidance is will be provided to;

- explain why an Asset Management Risk Framework is required and how it should be used. 
- describe the overarching processes (workflows) associated with framework.

- incorporate the guidance developed in previous product groups, describing tier 1, 2 and 3 methods and tools for specific asset types.

- includes examples to illustrate application of the methods.

- discusses limitations of methods and reasons to switch between tiers.

By providing practical examples and supporting practitioners in correctly using the framework, FCERM authorities will be better placed to achieve the benefits associated with use of the framework. The guidance will improve understanding of the trade-off between maintenance cost and risk against the cost of deploying such tools, especially where the levels of potential risk and the costs of maintenance are low.

\section{Acknowledgements}

This project is the final part of a phased research programme on asset tools led by the Environment Agency and completing in 2016. The current phase is in partnership with $\mathrm{CH} 2 \mathrm{M}$ Halcrow, Royal Haskoning DHV and HR Wallingford. It builds on both the tools and research generated in the Performance-based Asset Management System (PAMS) project $[14,15]$, the previously phased research scoping project and delivering the inspection framework developed in association with Black and Veatch and John Chatterton Associates [5].

\section{Further Information}

For further information on research under the UK's joint Flood and Coastal Erosion Risk Management Research and Development programme refer to http://evidence.environmentagency.gov.uk/FCERM/en/Default/FCRM.aspx . Here you can subscribe to a newsletter and be kept informed of research developments such as this one.

\section{References}

1. Mitchell, C; Woodley, K; Neve, P; Wicks, J; Flikweert, J; Simm, J. (2016) Asset management planning - providing the evidence to support robust and risk-based investment decisions, Environment Agency Flood and Coast Conference. www.floodandcoast.com
2. Barlow, J. (2016) Creating Asset Management Capacity CAMC. Environment Agency Flood and Coast Conference Proceedings www.floodandcoast.com/abstracts/jbarlow.pdf

3. Panzeri, M. State of the Nation: Recent Advances in the NaFRA Analysis (2015), HR Wallingford Workshop Presentation www.eci.ox.ac.uk/research/water/forum/w1panzeri.pdf

4. Modelling Decision Framework - MDSF2 (2015) www.gov.uk/government/publications/modellingdecision-support-framework-mdsf2-for-flood-riskmanagement-strategies

5. Asset inspection APT (2016)

http://evidence.environmentagency.gov.uk/FCERM/Libraries/FCERM Project_Docu ments/APT 2 report.sflb.ashx

6. Risk of Flooding from Rivers and Sea (NaFRA) (2016) www.findmaps.co.uk/packages/Flooding/Predictedflood-risk

7. FACet - Flood and coastal erosion risk management Long-term investment scenarios (LTIS) (2014)

www.gov.uk/government/uploads/system/uploads/attach ment_data/file/381939/FCRM_Long_term_investment_s cenarios.pdf

8. Concepts and science for coastal erosion - an introduction to the Conscience framework. (2011) Marchand, M.and Sanchez-Arcilla, A. and Ferreira, M. and Gault, J. and Jiménez, J.A. and Markovic, M. and Mulder, M. and van Rijn, L.C. and Stanica, A. and Sulisz, W. and Sutherland, J. Ocean and Coastal Management, 54 (12). pp. 859-868.

9. Channel Coastal Observatory (2016) www.channelcoast.org

10. CoaEST (2016) www.ox.ac.uk/research/researchimpact/calculating-risks-coastal-flooding-and-clifferosion

11. iCOASST (2016) www.icoasst.net

12. Channel Management Handbook (2015) www.gov.uk/government/publications/channelmanagement-handbook-for-flood-risk-management

13. Risk Assessment of Coastal Erosion (RACE) (2007) http://evidence.environmentagency.gov.uk/FCERM/Libraries/FCERM Project_Docu ments/FD2324 7453 TRP pdf.sflb.ashx

14. Performance Based Asset Management R\&D phase 2

(2012) http://evidence.environmentagency.gov.uk/FCERM/en/Default/FCRM/Project.aspx? ProjectID $=044 \mathrm{e} 9 \mathrm{~b} 3 \mathrm{~d}-9191-4484-858 \mathrm{e}-$ 415e5c6272e6\&PageID=25ed1548-e 755-452a-9d94f2fc7d984e56

15. Simm J., Wallis M., Sayers P., Gouldby B., Buijs F., Flikweert J.-J. \& Hamer B. (2006) Developing a performance-based management system for flood and coastal defence assets. Proceedings of the 41st Defra Flood \& Coastal Management Conference, Defra, York, London. Paper 09. 